\title{
Engineering and Economic Perspective in The Production of $\mathrm{Cu}$ Nano
}

\author{
Annisa Yuliandini, Asep Bayu Dani Nandiyanto \\ Departemen Pendidikan Kimia, Fakultas Pendidikan Matematika dan Ilmu Pengetahuan Alam, \\ Universitas Pendidikan Indonesia \\ Jln. Dr. Setiabudi 229, Bandung 40154 \\ E-mail: nandiyanto@upi.edu
}

\begin{abstract}
The purpose of this study is to analyze the production of copper nanoparticles ( $\mathrm{Cu}$ NPs) on an industrial scale in an engineering perspective and economic evaluation perspective. Energy is needed because of various energy related applications. Evaluation of $\mathrm{Cu}$ nanoparticles production in an engineering perspective is carried out from the selection of processes that are adapted to industrial scale, calculation of mass balance, to the adjustment of commercially available equipment. Evaluation of production from an economic point of view is done by calculating economic parameters: Gross Profit Margin, Internal Return Rate, Payback Period, Cumulative Net Present Value, Profitability Index, and Break Even Point. Briefly from the production process, we use Copper acetate hydrate $\left(\mathrm{CuAc}_{2} \cdot 2 \mathrm{H}_{2} \mathrm{O}\right.$ ) (as a source of $\mathrm{Cu}$ ), Tween 80 (polioxyethilena-(80)-sorbitan monooleate) and ethylene glycol (as a reducing agent). The engineering viewpoint shows this process is capable of producing $\mathrm{Cu}$ nanoparticles which can be used as conductive nanoionic. Economic evaluation determines the process is beneficial, discussing with positive values all economic parameters. However, for some variations this process is not profitable, so economic evaluation is needed.
\end{abstract}

Keywords: copper, economic perspective, engineering, industry, nanoparticles.

\section{INTRODUCTION}

$\mathrm{Cu}$ nanoparticles are used as catalysts because they are effective and capable of producing large quantities of product even under mild reaction conditions [1]. Due to exceptional thermal conductivity, electrical conductivity, and chemical and optical properties, copper nanoparticles (Cu NPs) have been widely used for purposes such as conductive nanoionik [2], optical nanodevices [3], catalysts [4], and antibacterial agents [5].

Several methods such as chemical reduction [6], sonochemical reduction [7], microemulsion techniques [8], electrochemistry [9], hydrothermal [10], sol-gel synthesis [11], polyol processes [12] and microwave-assisted methods [13] is the primary technique for preparing copper nanoparticles from a bottom-up approach. Biological synthesis combines biological principles (reduction / oxidation) by microbial enzymes or plant phytochemicals with physical and chemical approaches to produce nanosize particles [14]. Top down methods for the synthesis of copper laser ablation nanoparticles, vapor phase synthesis [15], mechanical milling [16] and the release of pulsed wire (PWD) [17]. Various nanoparticles can be produced using top-down or physical methods with little change but the product quality is not good when compared to chemical methods and it requires special equipment and vacuum systems to produce nanoparticles. The most efficient method is the polyol method by reducing copper acetate hydrate in the literature [21], but there is no economic analysis of existing research for feasibility studies in large scale production. In fact, this information is important to provide better candidates for industry practitioners to apply this method in realistic applications.

Therefore, the purpose of this research is to evaluate the engineering in large scale $\mathrm{Cu}$ nanoparticles production using the polyol method to support this objective / study, we conducted variations in the prices of raw materials, electricity prices, employee numbers, and the price of tools in economic evaluation. We use paper [21] in the evaluation. The evaluation results obtained are the influence of the CNPV / Investment curve on Life Time (year) when variations are made. The impact of this study was to determine the evaluation of engineering on a large scale production of $\mathrm{Cu}$ nanoparticles.

\section{Synthesis of Cu Nanoparticles Using the Polyol Method}

Copper acetate hydrate $\left(\mathrm{CuAc}_{2} \cdot 2 \mathrm{H}_{2} \mathrm{O}\right)$, Tween 80 (polyoxyethylene-(80)-borbitan monooleate) and ethylene glycol. All chemicals are used without further purification. Nano copper particles are synthesized by adding copper acetate hydrate in a mixture of ethylene glycol and Tween 80. After that, the solution is separated from the residue with the filtrate. Copper deposits are washed with distilled water and then dried in the oven. To get the nano size, grinding is used to reduce the size to nanoparticles. The schematic process of synthetic Cu NP by the polyol method is shown in Fig.1.

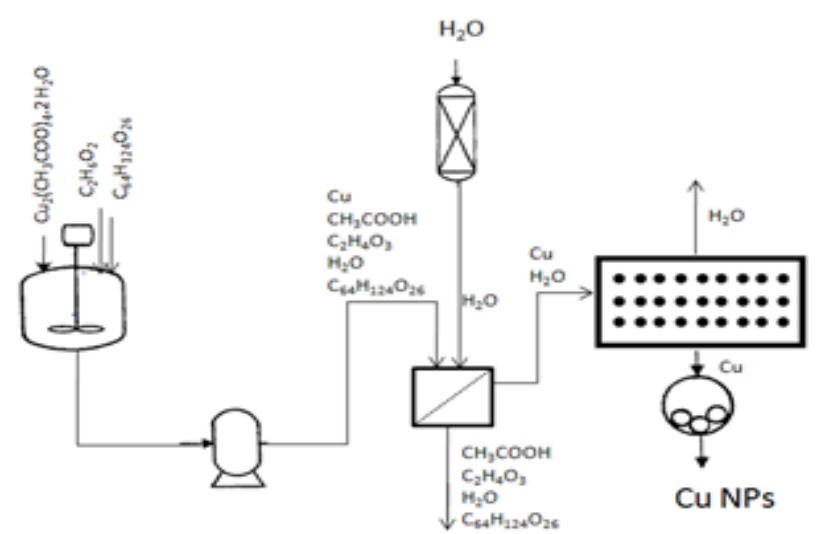

Fig 1. Schematic of the synthesis of $\mathrm{Cu}$ NP by the polyol method. 


\section{METHOD}

The synthesis of $\mathrm{Cu}$ nanoparticles evaluated engineering perspective with several economic evaluation parameters, such as gross profit margin (GPM), plant cost (PC), payback period (PBP), total manufacturing cost (TMC), cumulative net present value (CNPV). Process optimization to produce useful products and have economic value. The study begins by analyzing the plant's chain and needs, then analyzing financially for its industrial economy with the source of research assumptions already done. Hopefully this research provides useful information for further development.

In the economic evaluation analysis, we made several variations in the prices of raw materials, electricity prices, employee numbers, and equipment prices.

Several factors are assumed to analyze the economic perspective:

1. The exchange rate of USD (American currency) against IDR (Indonesian currency) has been determined that 1 USD $=14172$ IDR [18],

2. Prices of raw materials and tools are based on prices in the online buying and selling application (www.alibaba.com),

3. The production process is carried out in a place that has been purchased so that it is not necessary to pay rent for the place,

4. Depreciation occurs at each move by $5 \%$,

5. This production process takes 12 hours to produce $35 \mathrm{~kg}$ of $\mathrm{Cu}$ nanoparticles in one cycle,

6. $\mathrm{Cu}$ nanoparticle production process is done once a day,

7. 1 year $=300$ days,

8. The salary of 1 employee per year is 5294.63 USD.

9. The water used is obtained from rivers and treated using water treatment.

\section{RESULTS AND DISCUSSION}

\section{Engineering Perspective}

Some processes are assumsed in Fig. 1. Fig.1. shows the stoichiometry calculations after increasing the project which produced about $35 \mathrm{~kg}$ of $\mathrm{Cu}$ nanoparticles. Some of the raw materials used in this production are listed in Table 1 . We made an increase in $\mathrm{Cu}$ nanopparticles production by 50000 times and calculated based on the literature [19]. The increase in production was done because we did it on an industrial scale.

Table 1. Raw materials used

\begin{tabular}{ccc}
\hline $\mathrm{Cu}_{2}\left(\mathrm{CH}_{3} \mathrm{COO}\right)_{4} \cdot 2 \mathrm{H}_{2} \mathrm{O}(\mathrm{kg})$ & $\begin{array}{c}\mathrm{C} 2 \mathrm{H} 6 \mathrm{O} 2 \\
(\mathrm{~kg})\end{array}$ & $\begin{array}{c}\mathrm{C} 64 \mathrm{H} 124 \mathrm{O} 26 \\
(\mathrm{~kg})\end{array}$ \\
\hline 115 & 8400 & 14,715
\end{tabular}

The tools used in the production process of $\mathrm{Cu}$ nanoparticles are reactors, filtrator, water treatment, ovens, grinding, and pumps. We assume a $5 \%$ depreciation on each move.

In the process of producing $\mathrm{Cu}$ nanoparticles based on literature [19], all reactants are reacted to the reactor, followed by the pump filtration process. When filtration is needed for washing, water is obtained from river water that has been treated with water treatment. The result of filtration taken is residue which is $\mathrm{Cu}$ solid which still contains water. Then drying using an oven to remove water. $\mathrm{Cu}$ solids are still large, so grinding is done to produce $\mathrm{Cu}$ nanoparticles.

\section{Economic Evaluation \\ Ideal Conditions}

Fig. 2. shows the CNPV / Investment curve for Life Time (year) in ideal conditions. Changes occur annually within a period of 20 years. There was a decrease in CVPV / Investment from year 1 to year 2. In the third year, the increase in CNPV / Investment and this increase continues. Therefore, in the 7th year it reached the payback period (PBP) point. Before reaching the PBP point the increase occurred significantly, whereas after reaching the PBP point the increase that occurred was not significant.

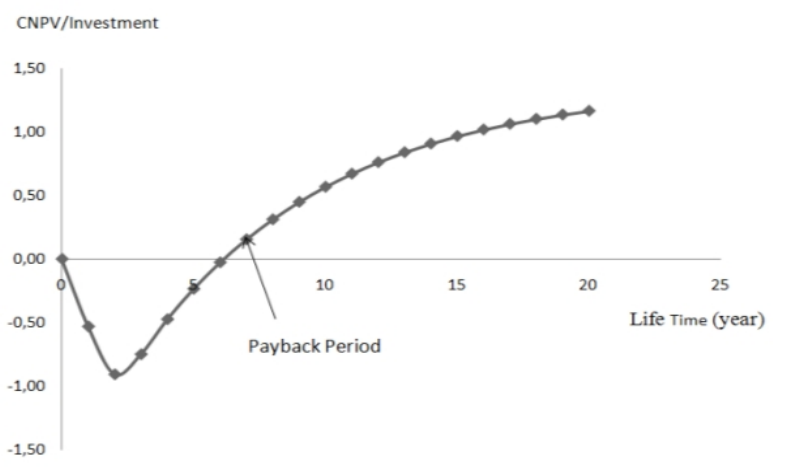

Fig. 2. Ideal condition for CNPV/Investment to Life Time (year)

The time period that we calculated for 20 years was due to the changes being seen clearly. The decrease in CNPV / Investment value in the first to second years was caused by the price of the equipment being too expensive so that the project suffered losses in the first to second years. But in the 3rd year, there was an increase in the value of CNPV / Investment because the project had begun to benefit and this increase occurred until the 20th year. In the 7 th year, the project reaches a payback period (PBP) point where the CNPV / Investment value reaches zero for the first time. The length of the project reached the PBP point due to the selling price of the product which was too cheap. Technical analysis shows that production can be carried out on a large scale [20]. After reaching the PBP point the increase in CNPV / Investment value is not too significant the possibility of the project being at the saturation point. If there is no new innovation then the curve will likely be a straight line (no increase in CNPV / Investment value). Thus the $\mathrm{Cu}$ nanoparticle project can be considered a profitable project.

\section{Variation in Changes in Prices of Raw Materials}

All conditions explained can be seen in Fig. 3. The first variation is the variation in raw material price changes in the 5 conditions. The first condition is when raw material prices are $90 \%$, which means that raw material prices are reduced by $10 \%$. The decline in the price of raw materials 
may occur if the raw material becomes easily found or purchases in very large quantities. This first condition shows a very positive change because it is above the ideal curve. This means that if the price of raw materials is reduced to $90 \%$ of the price of raw materials under ideal conditions, the project will get a very high CNPV / Investment value. In this condition PBP point is also in the 4 th year, meaning that the benefits gained by the project in this condition are greater than in ideal conditions.

The second condition is when the price of raw materials is $95 \%$, which means the price of raw materials is reduced by $5 \%$ from the price of raw materials in ideal conditions. This condition curve is far below the first condition curve, this is caused by the difference in profits that can be obtained by the project. In this condition, the PBP point is reached in the 5th year. Then PBP in this condition is slower than the first condition.

The third condition is when the price of raw materials is $97.5 \%$, which means the price of raw materials is reduced by $2.5 \%$ from the price of raw materials in ideal conditions. This condition curve is very close to the curve in the ideal conidis, this is because the difference is only $2.5 \%$. But in this condition, the PBP point is reached in the 6 th year. The achievement of PBP points in this condition is faster than the achievement of PBP points in ideal conditions. this shows the benefits that can be greater than the benefits under ideal conditions.

The fourth condition is when the price of raw materials is $100 \%$, which means the prices of raw materials are in ideal conditions. the fifth condition is when the price of raw materials is $102.5 \%$, which means the price of raw materials increases by $2.5 \%$ from the price of raw materials in ideal conditions. This condition curve is under the ideal condition curve, this is caused by the benefits obtained by the project is less than the benefits under ideal conditions. because the benefits gained less then affect the achievement of PBP points. The PBP point was reached in the 13th year, this achievement was very slow compared to the achievement of the PBP point under ideal conditions. It is appropriate that when the variable costs of more than $100 \%$ results exceed the minimum PBP, the project becomes unprofitable.

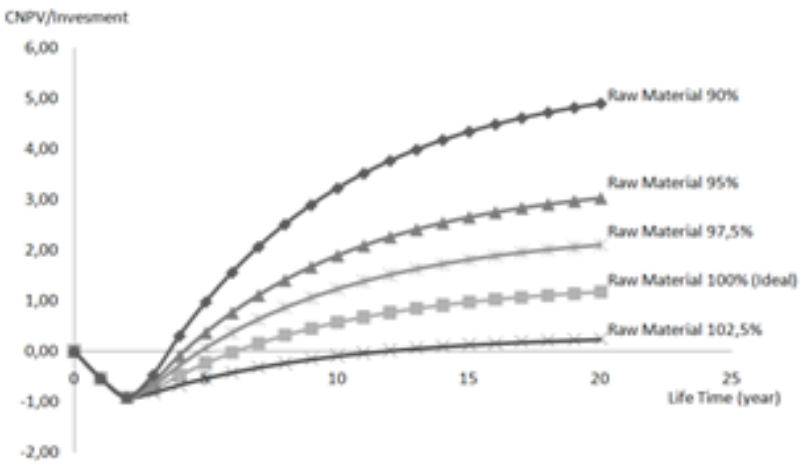

Fig. 3. The curve of CNPV under various condition

\section{Variation in Changes in Electricity Prices}

The second variation is the variation in the price of electricity per $\mathrm{kWh}$. All analyzes were compared with the condition of banks and Indonesian currencies [22]. The difference in CNPV / Investment value in each condition in
Fig. 4. is not too significant, it can be seen in Figure 4. The increase in electricity prices by 00.03 USD in each condition in 5 conditions. PBP point is reached in the 7 th year in all conditions. This shows that the price of electricity does not really affect the value of CNPV / Investment.

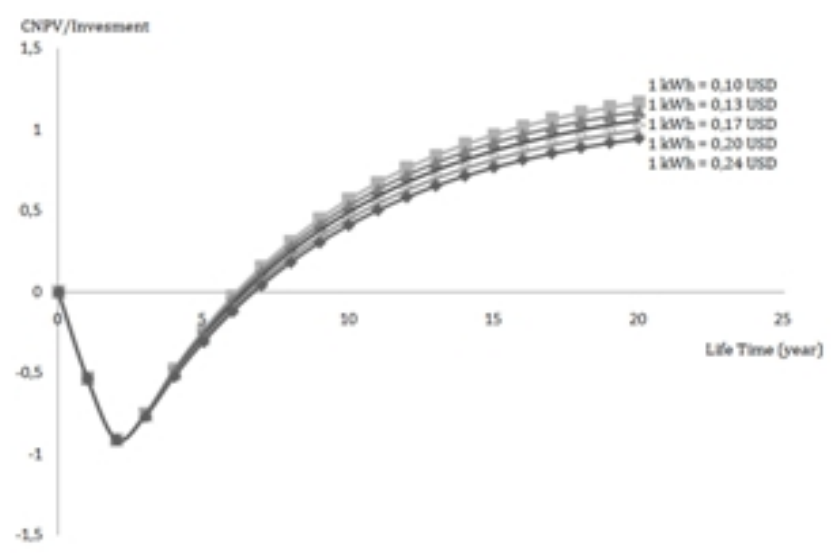

Fig. 4. The curve of CNPV under various condition

\section{Variation of Change in Number of Employees}

The third variation is the variation in the number of employees. This variation is carried out on 5 conditions where each condition has an increase in the number of employees by 3 people, can be seen in Fig. 5. Curve condition 1 and condition 2 are very effective, this is because the benefits obtained are not too much reduced if the number of employees increases 3 people. The $3 \mathrm{rd}$ condition curve means 7 employees, the curve is under the 1 st and 2 nd conditions curve. this shows that the addition of employees to 7 employees will have an effect on the value of CNPV / Investment, which means also affects the benefits gained. But in the 1 st to 3 rd condition curve it reaches the PBP point in the same year, namely in the 7 th year. Whereas in the 4 th condition when the number of employees reaches 10 people the achievement of PBP points becomes slow, namely in the 8th year.

In the 5th condition, when the number of employees reaches 13 people, the achievement of PBP points is slower, namely in the 9th year. This shows that if you want to keep reaching the PBP point in the 7th year, the maximum number of employees is 7 people. Projects are only profitable under certain economic conditions [20].

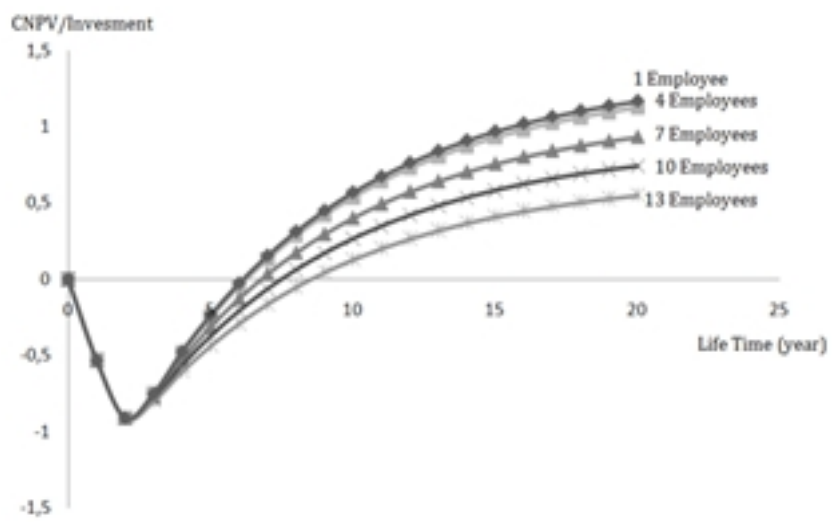

Fig. 5. The curve of CNPV under various condition 


\section{Variation in Tool Price Change}

The fourth variation is the variation in equipment prices under 5 conditions. Variations in the price of equipment continue to increase from the price of equipment in ideal conditions, can be seen in Fig. 6. Changes in economic conditions can affect the benefits of the project [21]. But the increase is only $2 \%$ in each condition. The 1 st condition is the ideal condition where the price of the equipment is $100 \%$. In the 2 nd condition when the price of equipment is $102 \%$, it means the price has gone up by $2 \%$. The increase in the price of this equipment affects the value of CNPV / Investment, it can be seen in Fig. 6. that the current curve of equipment prices $102 \%$ is below the curve when the price of equipment is $100 \%$ (ideal conditions). The achievement of PBP point in the 2nd condition is the same as in the ideal condition in the 7th year. The third condition is when the price of equipment increases to $104 \%$, there is an increase of $4 \%$ from the price of the equipment in ideal conditions. This increase greatly affects the curve, it is evident that the PBP point was reached in the 8th year, meaning that this condition greatly affected the project. In the 4 th condition when the price of equipment is $106 \%$, the achievement of PBP points is slower, namely in the 9th year. And in the 5th condition when the price of equipment is $108 \%$, the PBP point achievement is also more dense, namely in the 10th year. Therefore, if the project still wants PBP in the 7th year. Then the maximum increase in the price of equipment is $4 \%$ of the price of equipment in ideal conditions.

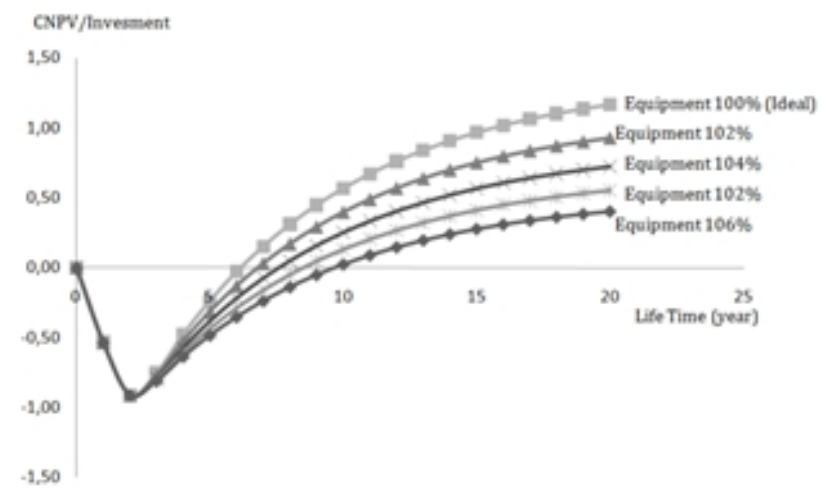

Fig. 6. The curve of CNPV under various condition.

\section{CONCLUSION}

Based on the results of the analysis, the prospective $\mathrm{Cu}$ nanoparticle project from the initial economic analysis. All analyzes were compared with the condition of banks and Indonesian currencies. This project is considered profitable if the increase in raw materials costs is $4 \%$ of the estimated ideal raw materials costs, the increase in the price of equipment will be $102 \%$ of the ideal conditions and the maximum employee is 7 people. The variation in electricity prices per $\mathrm{kWh}$ does not significantly affect the project analysis.

\section{REFERENCES}

[1] M. Kidwai, S. Bhardwaj, N. K. Mishra, V. Bansal, A. Kumar and S. Mozumdar. (2011). "Application of mobilized $\mathrm{Cu}$-nanoparticles as heterogeneous catalyst for the synthesis of a-amino phosphonates via A2-P coupling". Catal. Sci. Technol, 1, 426-430.

[2] Lee, Y.; Choi, J.-R.; Lee, K. J.; Stott, N. E.; Kim, D. (2008). "Large-scale Synthesis of Copper Nanoparticles by Chemically Controlled Reduction for Applications of inkjet-printed electronics". Nanotechnology, 19, 415604.

[3] Tanabe, K. (2007)." Optical Radiation Efficiencies of Metal Nanoparticles for Optoelectronic Applications". Mater. Lett., 61, 4573-4575.

[4] Isomura, Y.; Narushima, T.; Kawasaki, H.; Yonezawa, T.; Obora, Y.( 2012). "Surfactant-free Single-nano-sized Colloidal $\mathrm{Cu}$ Nanoparticles for Use as an Active Catalyst in Ullmann-coupling Reaction". Chem.Commun, 48, 3784-3786.

[5] Ramyadevi, J.; Jeyasubramanian, K.; Marikani, A.; Rajakumar, G.; Rahuman, A.( 2012). "Synthesis and Antimicrobial Activity of Copper Nanoparticles". Mater. Lett., 71, 114-116.

[6] Tan, K. S., \& Cheong, K. Y. (2013). "Advances of $\mathrm{Ag}, \mathrm{Cu}$, and $\mathrm{Ag}-\mathrm{Cu}$ alloy nanoparticles synthesized via chemical reduction route. Journal of Nanoparticle Research", 15(4).

[7] N.Wongpisutpaisan, N. Vittayakorn, A. Ruangphanit and W. Pecharapa. (2013). "Cu-doped Ti) $)_{2}$ nano powders synthesized by sonochemical assistedprocess". Sains Malaysiana 42,175.

[8] Kitchens, C. L., \& Roberts, C. B. (2004). "Copper Nanoparticle Synthesis in Compressed Liquid and Supercritical Fluid Reverse Micelle Systems". Industrial \& Engineering Chemistry Research, 43(19).

[9] Tamilvanan, A., Balamurugan, K., Ponappa, K., \& Kumar, B. M. (2014). "Copper Nanoparticles: Synthetic Strategies, Properties and Multifunctional Application". International Journal of Nanoscience, 13(02).

[10] Shah, M. A., \& Al-Ghamdi, M. S. (2011). "Preparation of Copper $(\mathrm{Cu})$ and Copper Oxide $\left(\mathrm{Cu}_{2} \mathrm{O}\right)$ Nanoparticles under Supercritical Conditions". Materials Sciences and Applications, 02(08).

[11] J. C. Wu, I.-H. Tseng and W.-C. Chang, J.(2001)." Photoreduction of $\mathrm{CO} 2$ using sol-gel derived titania and titania-supported copper catalysts". Res. 3, 113.

[12] R. S. Akpanbayev, B. Mishra, A. O. Baikonurova,G. A. Ussoltseva and A. P. Kurbatov, Int. J.(2013). "Features of The Electrolytic Copper Powder Deposition in the Presence of Polyols". Sci. 8, 3150.

[13] Q. Xu, Y. Zhao, J. Z. Xu and J.-J. Zhu.(2005). "Preparation of functionalized copper nanoparticles and fabrication of a glucose sensor.Actuators B": Chem. 114, 379.

[14] Shobha G, Vinutha Moses \& Ananda S. (2014). "Biological Synthesis of Copper Nanoparticles and its impact - a Review". India : International Journal of Pharmaceutical Science Invention.

[15] Nasibulin, A. G., Petri Ahonen, P., Richard, O., \& Kauppinen, E. I. (2000). "Copper and copper oxide nanoparticle formation by chemical vapor nucleation 
from copper (II) acetylacetonate". Journal of Aerosol Science, 31, 552-553.

[16] Amrollahi, P., Ataie, A., Nozari, A., \& Sheibani, S. (2013). "Synthesis and Characterization of $\mathrm{CuNi}$ Magnetic Nanoparticles by Mechano-Thermal Route". Journal of Superconductivity and Novel Magnetism, 27(2), 481-485.

[17] Das, R., Das, B. K., Shukla, R., Prahabaran, T., \& Shyam, A. (2012). "Analysis of electrical explosion of wire systems for the production of nanopowder". Sadhana, 37(5), 629-635.

[18] Bank Indonesia. Informasi Kurs. Bi.go.id/moneter/informasi-kurs/transaksibi/default.aspx.(2019).

[19] Ramyadevi, J., Jeyasubramanian, K., Marikani, A., Rajakumar, G., \& Rahuman, A. A. (2012). "Synthesis and antimicrobial activity of copper nanoparticles". Materials letters, 71, 114-116.

[20] Prabowo, Bagas, Thiya Khairunnisa, Asep Bayu Dani Nandiyanto. (2019). "Economic Perspective in the Production of Magnetite (Fe3O4) Nanoparticles by Co-precipitation Method". Bandung : WORLD CHEMICAL ENGINEERING JOURNAL (WCEJ).

[21] Maymuna,Annisa, Windy D. Annisa, Asep Bayu Dani Nandiyanto*, Risti Ragadhita. (2019).” Economic Perspective in the Production of Silver Nanoparticles on the Bacterial Cellulose Membrane as Antibacterial Material". Bandung : International Journal of Energetica (IJECA).

[22] Nandiyanto, A.B.D. \& Risti Ragadhita. (2018). "Evaluasi Ekonomi Perancangan Pabrik Kimia". Bandung: UPI Press. 